\title{
Adjusting Lecture Style To Accommodate Student Reading Habits
}

Richard R. Socash, (Email: socash@mscd.edu), Metropolitan State College of Denver

\begin{abstract}
The reasons behind the reading habits of undergraduate MIS students were examined to learn from the students' point of view why many don't read the textbook. Willingness to work hard on homework and project assignments and an appreciation of what is expected of them appears to be in place. However, carrots, sticks, ruses and requests all meet with limited success when used to encourage reading assigned material. Four sections of a required business school 2000-level MIS course were asked to respond anonymously to a questionnaire covering the course, textbooks, instructors, and personal reading habits. Follow-up discussions in the classroom and with individuals volunteering comments provided additional insight. In open discussions, one is led to believe limited time is the principal determining factor affecting reading habits. In the questionnaire, admitting to not understanding the textbook material followed by lack of interest in the subject exceeded limited time as the main reasons for not reading. Lack of interest can often be overcome by changes in instruction style and emphasis. Working around or compensating for deficient reading skills is a more difficult challenge. An analysis of the findings is presented in this paper along with the author's reactions and thinking on restructuring lecture sessions, reading assignments, and presentation practices for teaching undergraduate MIS courses.
\end{abstract}

\section{INTRODUCTION}

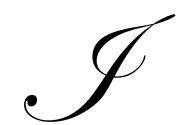

$\mathrm{n}$ the mid 1950's a controversial book [1] argued that students can't read because they are taught using a flawed system of reading instruction. Today, it seems many students won't read and is it perhaps because lectures on textbook material are based on an equally flawed approach? In business and the military, requests from superiors are interpreted as orders and carried out. Now move to the instructor-student situation at the college level where even grade pressure doesn't always get students' attention and compliance in reading textbooks. A course is designed to have students read and study the textbook prior to the lectures. The students are given the reasons behind the plan and occasionally nudged by quizzes on the assigned material and they still fail to read and go over it in a manner consistent with the instructor's expectations. Before implying this is general across the college spectrum, two qualifying points need to be stated:

- The students included in this study attend a "college of opportunity" where admission requirements are reduced to having a high school diploma or a GED certificate. Most work in addition to carrying a full academic load, and on average are several years older than their counterparts at other institutions.

- The author is out of the norm for teaching in a business school: a physicist by formal education, retired after twenty-six years as CEO of a software development corporation, and only recently back into academic instruction in a School of Business Computer Information Systems department.

Students readily admit to not reading assigned material, most often using an excuse of "no time." Discussions in class and one-on-one invariably touch on textbook size, presentation style, content and visual format. What effect these have on reading habits and what are the real reasons behind the practices appear to be more involved than a lack of time or interest. This past semester afforded an opportunity to examine this problem. The author was tasked with teaching four sections of a sophomore-level Introduction To Computers in Business course. This course is required for all majors in the Metropolitan State College of Denver School of Business which includes six undergraduate departments, Accounting, Finance, Computer Information Systems, Economics, Management, and 
Marketing. Although intended to be taken in the sophomore year, a number of students are junior and senior level, and also as a consequence of the course demands, many are second-time enrollees. For many in their sophomore year, this is often their first encounter with a difficult or demanding course and the first time they have been required to go beyond passive class attendance and minimal homework assignments. All four sections in the study had the same instructor, assignments, lectures, lab and exam schedules and instructor access. Course content included coverage on computer hardware, software, and architecture, telecommunications, data organization, internet operations and applied business systems. Lab sessions covered in greater depth Windows and Unix operating system usage and comparisons, and Microsoft Excel and Access case work. Course objectives were designed to introduce students to computer usage in business and to have them develop an intermediate skill level in using Office tools such as Excel and Access.

\title{
METHODOLOGY
}

To develop a starting point for this study, a questionnaire (seventy-six questions) was given to the students. It was not designed for correlated statistical analysis but rather to get a qualitative sense of their reading habits and how they view the usefulness of their textbooks and supplemental handout information. It was structured to allow for an easy "agree-disagree, neutral, or positive-negative" answer expression by the students. Question sense was varied to give balance to both positive and negative responses and reformatted repeat questions were added to validate answer consistency. Students were asked to react and give quick responses rather than analyze individual questions in detail. Because the conditions for all four sections were constant, the results were combined in the analysis. Also, in analyzing the data, the response values of strong agreement and agreement were combined into a single positive response and similarly, disagree and strongly disagree responses were combined into a single negative response. Following an initial assessment of the results, a series of in-class discussions was carried out to get expanded information and opinion on selected topics. These discussions were informal in nature and no attempt was made to maintain content or subject consistency among the four classes. Often, comments relating to student entertainment interests were made to provoke response and discussion. Student opinion was also sampled by talking to students on a one-on-one basis when they stopped in for assistance with homework and project assignments or to turn in completed work. In the course of these discussions, a suspicion was confirmed that the author's view of reading and studying material differed significantly from the typical student view. [3] Whereas the author believes studying material involves developing an understanding by thinking about points after reading, and committing important ones to memory, studying for many students seems to be reduced to a quick reading of the assigned material with follow-up considerations only when given specific assignments or directions on the material. In the absence of instructor emphasis, students attached little importance to major points of information and were unable to argue why specific items were deemed sufficiently important to be included in the text and/or class lectures.

The figure below includes a sample of the questions showing responses to a subset of questions relating to textbook preferences and reading habits.

\begin{abstract}
ANALYSIS
At the time of this study, faculty members involved with the course were selecting a new textbook for the Fall 2006 session. Publisher representatives were frequent visitors to the campus and there were opportunities to examine various texts and textbook styles and to talk directly with authors promoting their work. A revealing disclosure was the statement from a publisher representative that "we're trying to give textbooks a magazine look." Pictures, cartoons, style changes, bleeds and cuts are added less for reader comprehension and content clarification, and more for visual impact. [2] Something that can be presented in a clear and concise single-paragraph exposition is now an entire $8.5 \times 11$ inch page supplemented with visual elements intended to attract attention. The publisher's intent is to have one or two points per page register with the student who is expected to "look at" rather than "read" the content. Questionnaire results and discussions with students confirm a preference for the magazine-formatted text as opposed to the traditional black and white text with limited figures and pictures. Discussions confirmed this preference is driven primarily by familiarity and ease of effort rather than comprehension assistance. Their position appears to be, "I want my texts to look like my magazines and entertainment elements" and unfortunately, comprehension and retention of useful information from the texts appears to be comparable to that from the entertainment elements.
\end{abstract}


Figure 1: Example Questions From Student Questionnaire

\begin{tabular}{|c|c|c|c|}
\hline Question & Positive & Negative & Neutral \\
\hline The pictures in the textbook are useful for understanding the text information & 54 & 7 & 20 \\
\hline The textbook chapter summaries are useful for understanding the material & 61 & 5 & 17 \\
\hline Questions within the text would aid in understanding the material & 50 & 6 & 24 \\
\hline Most course-assigned readings are interesting and informative & 17 & 37 & 30 \\
\hline Lack of interest is the most important reason for not reading textbooks & 46 & 22 & 14 \\
\hline Limited time is the most important reason for not reading textbooks & 45 & 15 & 21 \\
\hline Textbooks for the most part, are easy to read and understand & 36 & 26 & 23 \\
\hline Textbook chapters, for the most part are of reasonable length. & 23 & 42 & 20 \\
\hline Textbooks for the most part are of proper length & 20 & 41 & 28 \\
\hline Graphs and pictures are helpful to understanding subject material. & 68 & 2 & 15 \\
\hline Pictures, cartoons and diagrams make textbooks more interesting & 63 & 6 & 15 \\
\hline Textbooks should include more easy to follow/easy to understand visuals & 47 & 8 & 20 \\
\hline Handouts and instructor's notes are more likely to be read than a textbook & 65 & 7 & 14 \\
\hline Smaller texts without pictures are preferable to larger texts with pictures & 16 & 47 & 21 \\
\hline Reading habits of most students are determined by individual instructors & 38 & 19 & 26 \\
\hline Shorter chapters would encourage more students to read the textbook & 63 & 5 & 9 \\
\hline
\end{tabular}

Information overload also appears to be real for many. The amount of information the typical student is exposed to from all sources is quite high and appears to be increasing. This takes the form of cell phone conversation, portable music, instant messaging/email, hand-held gaming devices and on-line computer activity. Casual observation in the student labs shows many "surfing" with surprisingly short screen exposures even when topics appeal to their interests. A habit of "see and absorb" from the computer screen is paralleling the "see and absorb" practice one develops from looking at television and movie screens. Questioning students on the amount and detail level of retention is met with claims of reasonably high comprehension and retention. Further discussion reveals a less than claimed level of content retention and little if any problem solving and analysis activity. In general, the lifestyle for many of today's students seems to provide little time for contemplation or critical thinking other than as a response to an immediate problem or demand. Entertainment has overtaken learning and self-improvement even at the textbook study level.

It's understandable that students are reluctant to admit to not understanding textbook material. Most inquiries that might be interpreted as questioning their competence in comprehending the material provoke a defensive response designed to offer reasons for not examining the material in the depth necessary to provide proper comprehension. When asked to explain or elaborate on a passage they claim to understand, many students fail to give an acceptable explanation or content exposition even when they strongly believe they know what it means. This cannot be attributed to poor writing or speaking skills, and is only partly explained away by limited skill in organizing and presenting arguments. How often have we heard, "I understand the material, but when it comes time for the test, my mind goes blank."

Writing skills and reading comprehension are strongly coupled for most people. When looking at the general level of writing skills for this student sample, it is apparent that significant improvement is needed to match industry and business expectations. Based on the author's experience, minimally acceptable writing skills in the business world frequently go unchallenged in the academic world for both student and faculty authors. Spell checking tools whose use is encouraged, catch errors in spelling but leave in place grammatical and syntactical problems and appear to be creating a false confidence on the part of many students who fail to recognize differences between words such as whether and weather or their and there. The trend to totally relax writing discipline in email messaging also has a cost which shows up in the more formal assignment writings and subjective portions of exam responses. It's difficult to avoid drawing a comparison between one's organization of ideas in writing and in thinking. In examining a student's response to an exam question that contains one or more key words in an incorrect context, the author is led to believe this is more the result of deficient comprehension rather than an inability to express ideas in written form or because of 
limited vocabulary skills. How much effort should be devoted to correcting writing problems or even pointing out errors is an unanswered question at this time.

Poor reading habits also enter in. Experts have examined and developed accepted models for overall learning styles and for component elements such as reading and comprehension. Once identified and given the opportunity to work one-on-one with a remediation specialist, measurable improvement can be seen for many poor readers and learners. Again, it's a matter of time limitation and course objectives which determine what assistance if any can be given to these students by their instructors. Given the fact that a significant percentage of the student population is deficient in reading skills, it is more realistic to redesign a portion of the course presentation to compensate for this deficiency rather than trying to correct the problem at the individual student level.

Intimidation by volume is another factor that needs to be considered. Even a moderately interesting magazine is skimmed by most rather than read in detail for comprehension. Most textbooks, according to students, are not interesting, and even when configured into a magazine format, don't capture the interest of the student reader. A typical textbook in the undergraduate Business IS/IT area will often contain seven to nine hundred pages, of which perhaps a hundred can be dismissed as subject support material such as introductions, content lists, chapter dividers, questions, and an index and glossary. What remains for a fifteen week course is forty-plus pages of reading each week. This is a modest amount for the student with good skills, but a real problem for the poor reader who is tasked with reading, comprehending, and analyzing the material for subsequent problem solving, content discussions, and examinations. Important ideas and concepts are often introduced and explained in a few sentences. It's not unusual to have a number of important concepts covered in a single page with the result that unless the student develops and practices a methodology for recognizing and extracting important points, spending four or five minutes on a page will not yield a useful comprehension result. Few if any students I talked with say, "I'll at least read and understand the first few pages." If they encounter difficulties, they often give up, thinking that an effort to get something out of part of the readings rather than understanding the entire assignment has little benefit and is not worth the effort.

It's also evident that many don't know how to apply themselves to the task of proper study. [4] For some students, this is the first demanding course they have taken. It's a required course they didn't elect, it covers a subject easily perceived by them as boring, and they walk into class the first day having no idea of its relevance. An attitude of "I dare you to teach me something" is written on a number of faces. All of this coupled with having to accommodate a higher level of expectation and effort starts things off on a wrong footing. The survey indicated a number of students are still operating at an "extension of High School" level, applying the same amount of interest, attention, and effort to course work. In the college setting this doesn't allow for success and depending on previously developed study habits, some are able to adjust and some are not.

A final point for consideration deals with expectation levels on the part of instructors and on the part of students. For many non-CIS majors, getting a $\mathrm{C}$ grade was the most important goal for this class. It is troubling when a student is content to settle for a C. The employees who were satisfied with just getting by were eased out of the organization and replaced with ones looking to excel. Many individuals comfortable with getting by at the college level maintain this attitude and don't fare well in the business world. As an instructor, regardless of the students' qualifications, it's preferable to think one is working with future business successes, not future business failures.

\section{FINDINGS}

There appears to be a measurable disconnect between student self-assessment of comprehension of textbook material and the actual level of comprehension. Discussions and review sessions before an exam show students feeling comfortable with the material and having high confidence levels for doing well. This same material is presented in an exam and performance is invariably well below expectations on the part of the students. This artificial comfort is not indolence or apathy, and is troubling in that many students go through their college program suffering more minor defeats than minor victories when the average needs to be seventy percent or better.

Many students do indeed read texts like they read a magazine. A conclusion drawn from the discussions and observations is that the reading methods of today's students differ from that of the author. When reading a textbook, 
students view in order: pictures, bold text, and then content text. This differs from the author's ordering of bold text, content text and then pictures, and leads to an unfortunate realization that the author's current approach to lecturing in support of the textbook is missing the very component considered most important by the students. The premise that pictures and figures are used to support the text appears to be reversed for many students. They view the text as supporting the information in the visual elements on the page. A casual question on what is the important or significant points of information on a page frequently elicited an answer linked to a visual element and not to the text. Because of this, a natural consequence of treating a textbook like a magazine or other entertainment item is that topics of major importance are determined, rightly or wrongly, from the visuals. Pictures that are too general or cartoons that are too subtle often lead to completely missing the important points on the page.

A final unsupported contention on the part of the author is that today's students process less of the textual input than students of a generation ago. Observations of students reading or working at a computer screen indicate a process of viewing and inputting information at a steady rate. The expected pauses to consider certain points or to reflect on the material just read appear to be missing.

\section{CONCLUSIONS}

- $\quad$ Students derive most of their textbook information from the visual elements on a page and not from the text.

- $\quad$ Actual comprehension levels are below self-assessed levels.

- $\quad$ Students' reading and studying patterns are heavily influenced by their visual entertainment patterns.

These points lead to the conclusion that to compensate for the current reading habits and competencies of students, the author needs to change his approach to lecturing and assigning reading material. Also, more guidance is needed to assist students in reading and studying textbooks for content comprehension. [5] Lectures need to remain tied to text content but must do so by increasing references to the visual elements identifiable with the more important concepts. This lends some support to the practice of organizing lectures around PowerPoint slide presentations, however relying on the standard sets of presentations that accompany contemporary texts requires careful consideration since many students treat these sessions as valid substitutes for reading the textbook. Reference to a visual element must be accompanied by a reference to related supporting text. Explanation by the instructor needs to be integrated to allow the student to then read the text with an acceptable level of comprehension. Reading assignments need to be reformatted to direct student attention to specific passages considered most important by the instructor. The current approach of assigning a range of pages to be read needs to be supplemented with specific references to the important visual elements and directed attention to related paragraphs in the text which provide expanded coverage of important points. Assuming this approach works, an additional challenge will be to get students to read beyond the sections of the text singled out as being the most important.

A final point for consideration deals with the importance of generating student interest in the course. The "chip on the shoulder" many carry for required non-major subjects starts things off in a negative or at best, indifferent atmosphere. At the end of the term, a course evaluation as part of a formal writing assignment requested opinions and recommendations on the good and bad parts of the course. Grades for the writing assignment were based on writing style and format, and not on content. A majority of students, distributed across the grade spectrum, bought into the importance and value of the course based on what had been a continued effort to point out the relevance of certain topics to the students' current and future jobs and discussions on actual practices and experiences. The temptation to recount "war stories" from the author's business career was resisted and replaced by selected examples of how certain topics played out in real world instances. Actual cases from the text and the author's experience were integrated into the lectures to give students a clear and understandable picture of practices and behaviors in the boardroom as compared to the classroom. The overall result, confirmed by the students through the assessment report, was that skepticism was replaced by an acknowledgement of the value of the course and validity of the information presented. 


\section{REFERENCES}

1. $\quad$ Flesch, R. (1955), Why Johnny Can't Read, New York, Harper and Row.

2. Jones, R. (2001) U.S. Textbooks Are long on Glitz, But Where's the Beef? The Education Digest, 66(6), 2330 .

3. Lynch, D., (2005), Differences Between Student and Faculty Perceptions of Learning Strategies. The Teaching Professor, 19(10) 4-4.

4. McFarland, R., (2003), Teaching Students To Learn In The Computer Science And Information Systems Curriculum: Creating A Distinction Between Content And Methods, Journal of Computing Science In Colleges, 19(1), 235-244.

5. Taylor, I., (1998) Educating The Professionals. Adults Learning, 9(10) 24-25.

NOTES 